\title{
Effect of an eco-friendly plasticizer on rheological, thermal and mechanical properties of biodegradable poly(propylene carbonate)
}

\author{
Yanping Hao, $^{\text {a,b }}$, Huili Yang ${ }^{\text {a }}$, Huiliang Zhang ${ }^{a, *}$, Guibao Zhang ${ }^{\text {a }}$, Yungang Bai ${ }^{\text {a }}$ \\ Ge Gao ${ }^{b}$, Lisong Dong ${ }^{a}$
}

${ }^{a}$ Key Laboratory of Polymer Ecomaterials, Chinese Academy of Sciences, Changchun Institute of Applied Chemistry, Changchun, 130022, PR China

${ }^{\mathrm{b}}$ College of Chemistry, Jilin University, Changchun 130012, PR China

\begin{abstract}
A novel plasticizer poly(diethylene glycol adipate) (PDEGA) was synthesized via polyesterification reaction using diethylene glycol and adipic acid as raw materials. A series of poly(propylene carbonate) (PPC) blends were prepared by direct melt compounding with PDEGA as plasticizer. The miscibility, morphology, rheological properties, thermal behavior, and mechanical properties of the blends were investigated. The blends was an partially miscible system with PDEGA uniformly dispersed in PPC matrix. Rheological study concluded that both unplasticized and plasticized PPC exhibited a slightly shear thinning behavior at all angular frequency regions. Viscosities of blends decreased as PDEGA content was increased due to increasing in chain mobility in the system. The plasticization decreased the glass
\end{abstract}

*Corresponding author.

E-mail address: hlzhang@ ciac.ac.cn (H.L. Zhang)

Keywords: Biodegradable blend, Plasticizer, Rheological property, Thermal property, Mechanical property 
transition temperature, which was reflected in a lower tensile strength and improved elongation at break. The pyrolytic decomposition activation energies of PPC and PPC/10wt\% PDEGA were estimated via Flynn-Wall-Ozawa method.

\section{Introduction}

It is well known that the white pollution caused by petroleum-based materials has become an international environmental problem, and the shortage of petroleum resources has driven efforts to produce biodegradable or bio-based materials. Additionally, global warming, known as the greenhouse effect, is caused mostly by the massive release of carbon dioxide $\left(\mathrm{CO}_{2}\right)$ into the atmosphere [1]. Thus, the incorporation of $\mathrm{CO}_{2}$ into materials as a mean of sequestration has attracted scientific and practical interests recently as a mean to reduce greenhouse gas pollution and overcome shortages in classical fuel supplies.

Recently much effort has been made to develop biodegradable polymers from renewable sources, such as poly(lactic acid) (PLA) [2], polycapro-lactone (PCL) [3], poly(3-hydroxybutyrate) (PHB) [4], poly(propylene carbonate) (PPC) [5], thermoplastic starch (TPS) [6] and so on. Poly(propylene carbonate) (PPC) is a promising and biodegradable polymer prepared by polymerization of $\mathrm{CO}_{2}$ with propylene oxide $[7,8]$. It possesses excellent adhesion to cellulosic substrates and improved lubricity so that it has been used in binders [9], brazing pastes [10], and solutions, propellants [11] and diamond cutting tools [12]. Moreover, PPC is enzyme degradable [13], biocompatible [14] and readily processible [15]. It can also 
completely combust to produce only non-toxic carbon dioxide and water. However, it is brittle which leads to its limited applications. Blending with a low-mass molecular weight plasticizer or other polymers has often been carried out to improve certain properties of biodegradable polymers and to meet various practical requirements [5, $16-21]$.

Poly(diethylene glycol adipate) (PDEGA) is a novel plasticizer, which was synthesized in our laboratory. It has nontoxic and solvent resistance. Using nontoxic biodegradable macromolecular plasticizer is helpful to our environment [22]. In our previous work, we investigated the effect of PDEGA on the mechanical properties and thermal behaviors of PLA [23]. The results showed that PDEGA was an ideal plasticizer for PLA, and PDEGA plasticized blends exhibited good mechanical properties, and a lower glass transition temperature. However, no reports existed about PPC plasticized by PDEGA and its properties. PDEGA is a polymer of low volatility. So, PDEGA is chosen as a plasticizer for PPC. And we hope to obtain the plasticized PPC with lower glass transition temperature and high elongation at break which could be used to produce the casting film. In this study, PDEGA was melt blended with biodegradable PPC using a melt mixer. Differential scanning calorimetry (DSC), thermogravimetric analysis, tensile test, rheometer and scanning electronic microscopy (SEM) were used to investigate the effects of PDEGA on the thermal, mechanical, dynamic viscoelastic, rheological and morphological properties of the PPC/PDEGA blends. 


\section{Experimental}

\subsection{Materials}

PPC was supplied by Taizhou Bangfeng Plastic Co., Ltd. (China). The number average molecular weight $\left(M_{\mathrm{n}}\right)$ and polydispersity index (PDI) of the purified PPC were determined by GPC as $1.50 \times 10^{5} \mathrm{~g} / \mathrm{mol}$ and 4.32 , respectively. The chemical structure for PPC is presented in Scheme 1.

PDEGA was synthesized via polyesterification reaction using diethylene glycol and adipic acid as raw materials in our laboratory. In addition, tetra- $n$-butyl titanate and isooctanol were used as a catalyst and chain-ending reagent for the reaction, respectively, which were purchased from the Sinopharm Chemical Reagent Co., Ltd. PDEGA had molecular weight $\left(M_{\mathrm{w}}\right)$ of $3,096 \mathrm{~g} / \mathrm{mol}$ and polydispersity of 1.46 by GPC analysis. The chemical structure for PDEGA is presented in Scheme 2.<smiles>CC(CCCCO)OC(=O)O</smiles>

Scheme 1. The chemical structure for poly(propylene carbonate).

(1)<smiles>O=C(O)CCCCC(=O)OCCOCCO</smiles> 
(2)<smiles>O=C(CCCCC(=O)OCCOCCO)OCCOCCO</smiles><smiles>CC(O)C(C)(O)CCOCCOC(=O)CCCCC(=O)OCCOCCO</smiles>

Scheme 2. Synthesis of poly(diethylene glycol adipate) from adipic acid and diethylene glycol.

\subsection{Sample preparation}

Before processing, PPC was dried in vacuum oven at $45{ }^{\circ} \mathrm{C}$ for $8 \mathrm{~h}$. PPC/PDEGA blends with several selected weight ratios $(100 / 0,95 / 5,90 / 10,85 / 15$ and 80/20) were prepared by using a Haake batch intensive mixer (Haake Rheomix 600, Karls-ruhe, Germany) with a batch volume of $50 \mathrm{ml}$. The melt compounding was performed at $170{ }^{\circ} \mathrm{C}$ and a screw speed of $50 \mathrm{rpm}$ during a total mixing time of $5 \mathrm{~min}$, until the viscosity had reached a nearly constant value. After mixing, all the samples were cut into small pieces and then were hot-pressed at $170{ }^{\circ} \mathrm{C}$ for $5 \mathrm{~min}$ followed by cold-press at room temperature to form the sheets with thickness of $1 \mathrm{~mm}$. The compression molding steps were carried out carefully in order to obtain the same treatment for every sample.

\subsection{Characterization}

The cryo-fractured surfaces of the PPC/PDEGA blends selected alcohol removal of PDEGA component. The etching time was $30 \mathrm{~min}$. Cryo-fractured surfaces of PPC/PDEGA blends were characterized by a field emission scanning electron 
microscope (XL-30 ESEM FEG, FEI Co., USA). All samples were coated with a thin layer of gold of about $10 \mathrm{~nm}$ and an accelerating voltage of $10 \mathrm{kV}$ was used to produce the SEM photographs.

Melt flow index (MFI) is the melt flow rate index, expressed in grams, extruded isothermally in 10 min under constant load through a die of standard dimensions [24, 25]. MFI of the neat PPC and PPC/PDEGA blends were determined with a $\mu$ PXRZ-400B melt-flow indexer (Changchun, China) equipped with a standard die. The die had a smooth straight bore with a diameter of $2.0955 \pm 0.0051 \mathrm{~mm}$ and a length of $8.000 \pm 0.025 \mathrm{~mm}$. The measurements were performed according to ASTM D 1238-82. The investigated temperature was $170{ }^{\circ} \mathrm{C}$.

Rheological measurements of the blends were conducted with the rheometer (TA Instruments Co., AR 2000ex, USA) at $170{ }^{\circ} \mathrm{C}$. Frequency sweep for neat PPC and the PPC/PDEGA blends was carried out under nitrogen using 25-mm plate-plate geometry. The gap distance between the parallel plates was $0.9 \mathrm{~mm}$ for all tests. The sheet samples were about $1.0 \mathrm{~mm}$ in thickness. Storage modulus $\left(G^{\prime}\right)$, loss modulus $\left(G^{\prime \prime}\right)$, and complex viscosity $\left(\eta^{*}\right)$ were measured in the angular frequency sweep experiments performed over a frequency range of $0.1-100 \mathrm{rad} / \mathrm{s}$. The $\eta^{\prime}$, the real part of the complex viscosity and the $\eta^{\prime \prime}$, the imaginary part of the complex viscosity were calculated according to the following equations:

$$
\begin{aligned}
& \eta^{\prime}=G^{\prime \prime} / \omega \\
& \eta^{\prime \prime}=G^{\prime} / \omega
\end{aligned}
$$

The glass transition temperature $\left(T_{\mathrm{g}}\right)$ of neat PPC and PPC/PDEGA blends was 
determined by differential scanning calorimetry (DSC) (TA Instruments DSC Q20 USA) on the specimens sliced from compression molded samples. Samples (about 5-8 mg) were placed and sealed in aluminum pans. The samples were then heated from -60 up to $100{ }^{\circ} \mathrm{C}$ at $10{ }^{\circ} \mathrm{C} / \mathrm{min}$.

The $T_{\mathrm{g}} \mathrm{s}$ of the components were also studied by dynamic mechanical analysis (DMA, TA Instruments Co., DMA, Q800, USA). The dimensions of the samples were $20 \mathrm{~mm} \times 4 \mathrm{~mm} \times 1 \mathrm{~mm}$. The experiment was carried out in tension mode at a constant heating rate of $3{ }^{\circ} \mathrm{C} / \mathrm{min}$ and a frequency of $1 \mathrm{~Hz}$, from -80 to $80{ }^{\circ} \mathrm{C}$.

The thermal stability of materials was measured by thermogravimetric analysis (TGA, Perkin-Elmer TGA-7, USA) simultaneous thermal analysis instrument. The PPC/PDEGA samples with weight of $10 \pm 0.2 \mathrm{mg}$ were heated from room temperature to $600{ }^{\circ} \mathrm{C}$ at $10{ }^{\circ} \mathrm{C} / \mathrm{min}$ under nitrogen.

PPC and PPC/10wt\% PDEGA were subjected to the TGA in a nitrogen atmosphere. The experiments were conducted at four different heating rates $(5,10,20,30$ and 40 ${ }^{\mathrm{oC}} / \mathrm{min}$ ) from room temperature to $600{ }^{\circ} \mathrm{C}$.

The uniaxial tensile tests were carried out at room temperature on an 1121 testing machine (Instron Corporation, USA). Specimens $(20 \mathrm{~mm} \times 4 \mathrm{~mm} \times 1 \mathrm{~mm})$ were cut from the previously compression-molded sheet into a dumbbell shape. The measurements were conducted at a cross-head speed of $50 \mathrm{~mm} / \mathrm{min}$ at $23 \pm 2{ }^{\circ} \mathrm{C}$ according to ASTM D638-2008. At least five runs for each sample were measured, and the results were averaged. 


\section{Results and discussion}

\subsection{Miscibility of PPC/PDEGA blends}

Scanning electron microscope is an instrument used to analyze the miscibility of the blends. The etched surfaces of binary PPC/PDEGA blends are shown in Fig. 1. As observed in images, there were many microvoids in the PPC/PDEGA blends. The dispersed phase was finely and homogenously dispersed in the matrix of the blends with different content of PDEGA. With the increasing of PDEGA content, the diameters of the dispersed PDEGA phase were further broadened. Summing up the above phenomena, the PPC/PDEGA blends might be classified as immiscible or partially miscible. Similar microvoids were also observed in PLA/PDEGA, PHBV/ESO, PLA/PPG , and PLA/ESO blends [22, 26-28].

The efficiency and compatibility of plasticizer requires a similarity in solubility parameters between plasticizer and polymer [29, 30]. The miscibility of plasticizer and PPC could be estimated by comparing the solubility parameters $(\delta)$ of two molecules. The closer the $\delta$ values of the two molecules, the greater is the compatibility between PPC and plasticizer, and this plasticizer could decrease the glass transition temperature of PPC much more effectively. The solubility parameter $\delta$ can be calculated using the methods of Hoy [31]:

$$
\delta=\frac{\rho \sum F_{i}}{M_{0}}
$$

where $\delta$ is the solubility parameter, $\rho$ is the density, $M_{0}$ is the molecular weight, and $F_{\mathrm{i}}$ represents the group molar attraction constants. The corresponding data is shown in Table 1. The calculated the solubility parameter of PDEGA was close to that of PPC, 
which indicated that they should be partially miscible in blending. The effect of PDEGA on mechanical and thermal properties of PPC could also be explained in terms of solubility parameters of the plasticizer and polymer.

\subsection{Rheological analysis}

MFI index shows changes in material flowability which indicates changes in material structure. The MFI of neat PPC and PPC/PDEGA blends are determined, and the results are shown in Fig. 2. It could be noted that the MFI was gradually increased with the increasing of PDEGA content. Although the neat PPC had the MFI of 0.22 $\mathrm{g} / 10 \mathrm{~min}$, the MFI increased to $1.25 \mathrm{~g} / 10 \mathrm{~min}$ when the PDEGA content was $20 \mathrm{wt} \%$. In this work, PDEGA was a new type of plasticizer for PPC. When PDEGA was added in PPC, the PDEGA molecule diffused into PPC matrix by penetrating, which would make matrix slip and flow easier.

Dynamic melt rheological properties of neat PPC and PPC/PDEGA blends were measured to elucidate the melt processibility of the blends. The complex viscosity $\left(\eta^{*}\right)$ of neat PPC and PPC/PDEGA blends as a function of angular frequency $(\omega)$ are shown in Fig. 3. It could be observed that neat PPC exhibited shear thinning at all angular frequency region. Compared with neat PPC, the complex viscosities of PPC/PDEGA blends also showed a shear-thinning tendency the tendency became stronger with increasing PDEGA content. The complex viscosities of blends were substantially lower than that of neat PPC and decreased with the increasing of PDEGA content, which was a typical plasticizing effect. It indicated that the PDEGA 
in the blends acted as plasticizer and caused the increase of the free volume and the chains' mobility of PPC [32]. The decreased complex viscosity of the blend meant that the processability of PPC was improved apparently.

The rheological data are analyzed using the Cole-Cole plot, representing the relationship between the real $\left(\eta^{\prime}\right)$ and the imaginary $\left(\eta^{\prime \prime}\right)$ parts of complex viscosity. [33]. It has been reported that the plot can be used to analyze the miscibility of polymer blends [34-36]. A smooth, semicircular shape of the plotted curves would suggest good compatibility, i.e., phase homogeneity in the melt, and any deviation from this shape shows a nonhomogeneous dispersion and phase segregation due to immiscibility [37].The Cole-Cole plots for neat PPC and PPC/PDEGA blends were presented in Fig. 4. It could be observed that PDEGA and PPC were miscible (or at least finely dispersed) in the all PPC/PDEGA blends, as could be evidenced from the smooth semicircular shape of the plots. The fine dispersion was also demonstrated in Fig. 1.

The corresponding dynamic storage modulus $\left(G^{\prime}\right)$ and loss modulus $\left(G^{\prime \prime}\right)$ for neat PPC and PPC/PDEGA blends are shown in Figs. 5(a) and (b), respectively. As expected, the $G^{\prime}$ and $G^{\prime \prime}$ of PPC decreased with increasing PDEGA content over the entire angular frequency range. The lower $G^{\prime}$ values of the blends were supposed to be originated from the decrease in molecular entanglement in the blends. The PPC/PDEGA blends had lower $G^{\prime \prime}$ values than that of neat PPC over the entire frequency range. This was due to the fact that $G^{\prime \prime}$ represented the viscous behavior (i.e., the amount of energy dissipated), and the addition of PDEGA to the PPC 
produced a material with the lowest energy dissipation. From the view of miscibility of blends, the interaction between blends decreased to a certain extent at higher PDEGA content. Hence decreasing in amount of energy dissipated of blends melting with all load resulted in the decreased loss modulus [38].

\subsection{Dynamic mechanical properties}

The loss modulus $\left(E^{\prime \prime}\right)$ of the neat PPC and PPC/PDEGA blends were measured by DMA and the curves were shown in Fig. 6. The glass transition temperature $\left(T_{\mathrm{g}}\right)$ is an important indicator for mobility of chain segment. Therefore, plasticizing efficiency has been evaluated by the decrease of $T_{\mathrm{g}}$ as a function of plasticizer content $[39,40]$. The $T_{\mathrm{g}} \mathrm{s}$ are obtained from the $E^{\prime \prime}$ peak temperature and the $T_{\mathrm{g}} \mathrm{s}$ values are given in the Table 2. Neat PPC showed a sharp $E^{\prime \prime}$ peak at around $33.4{ }^{\circ} \mathrm{C}$. As the PDEGA was added, the $E^{\prime \prime}$ peak for the $95 / 5$ PLA/PDEGA blend shifted to a lower temperature at 25.0 ${ }^{\circ} \mathrm{C}$. It indicated that PDEGA as a plasticizer could increase segmental mobility of the PPC chains, which decreased the $T_{\mathrm{g}}$ of PPC. With the further increasing PDEGA content, two district glass transitions could be distinctively identified. The high temperature transitions around $20^{\circ} \mathrm{C}$ could be associated with the glass transition of PPC and the low temperature transitions around $-60{ }^{\circ} \mathrm{C}$ could be attributed to the relaxation of PDGEA. In addition, the two district glass transitions shifted to lower temperature as well with increasing amounts of PDEGA. The results indicated that the PPC/PDEGA blend was partially miscible, which is consistent with the analysis of solubility parameters. 


\subsection{Thermal properties}

Thermal properties of neat PPC and PPC/PDEGA blends were investigated by means of DSC and TGA. The DSC thermographs of neat PPC and PPC/PDEGA blends are shown in Fig. 7 and the corresponding parameters are given in the Table 2. It could be seen that a single $T_{\mathrm{g}}$ appeared for the PPC/PDEGA blend at a lower temperature than that for neat PPC and it gradually decreased to lower temperature with increasing PDEGA content in the blend. When $5 \mathrm{wt} \%$ PDEGA was added, the $T_{\mathrm{g}}$ decreased from $32.6{ }^{\circ} \mathrm{C}$ of neat PPC to $24.6^{\circ} \mathrm{C}$ and down to $14.2{ }^{\circ} \mathrm{C}$ when 20 wt $\%$ of PDEGA was added. Such decrease in $T_{\mathrm{g}}$ was commonly observed for plasticized PPC systems, indicating that PDEGA was an effective plasticizer for PPC.

The effect of the plasticizer on the thermal stability often takes into account when studying a plasticized polymer. One of most accepted methods to study the thermal properties of polymeric materials is thermogravimetry. The integral (TGA) and derivative (DTG) thermogravimetric curves provide information about the nature and extent of degradation of the polymeric materials. The TGA and DTG traces for PPC and PLA/PDEGA blends in nitrogen atmosphere are shown in Fig. 8 and the corresponding parameters are given in the Table 2. The thermal degradation behavior of various samples are compared using the initial decomposition temperature ( $\left.T_{\text {onset }}\right)$ and the temperature of maximum rate of weight loss $\left(T_{\max }\right)$ in order to understand the effects of PDEGA on the thermal degradation process of PPC. The data are listed in Table 2. Neat PPC started to decompose at $255.4{ }^{\circ} \mathrm{C}$. After that, the weight loss 
increased quickly, and the maximum degradation rate occurred at $268.4{ }^{\circ} \mathrm{C}$. The $T_{\text {onset }}$ of PDEGA was $218.6{ }^{\circ} \mathrm{C}$. The thermal degradation process of all blends had two stages in the temperature ranges of $230-260{ }^{\circ} \mathrm{C}$ and $260-350{ }^{\circ} \mathrm{C}$, as shown in Fig. 8 . The first stage might belong to the degradation of PPC and the second stage was the degradation of PDEGA. The $T_{\text {onset }}$ and $T_{\max }$ of PPC shifted systematically to lower temperatures with the usage of PDEGA plasticizer. This shift was globally more important when the amount of PDEGA was higher. For example, a shift from 255.4 ${ }^{\circ} \mathrm{C}$ to $233.5{ }^{\circ} \mathrm{C}$ and from $268.4{ }^{\circ} \mathrm{C}$ to $237.1{ }^{\circ} \mathrm{C}$ was observed for the $T_{\text {onset }}$ and $T_{\max }$ of the 80/20 PPC/PDEGA blend, respectively. The decrease of the PPC thermal stability was mainly because of the presence of PDEGA as plasticizer. PDEGA promoted a decrease in thermal stability by its action to intersperse itself around polymers and by breaking polymer-polymer interactions, which were predicted in the lubricity theory and gel theory of plasticization [41].

The dynamic TGA method was a promising tool to unravel the mechanisms of physical and chemical processes that occur during polymer degradation. Generally, for polymer degradation, all kinetic studies assume that the isothermal rate of conversion $d \alpha / d t$ is proportional to the concentration of reacted material. The rate of conversion can be expressed by the following basic rate equation:

$$
\frac{d \alpha}{d t}=k(T) f(x
$$

where $f(a)$ and $k(T)$ are function of conversion and temperature, respectively.

$k(T)$ is often modeled successfully by the Arrhenius equation:

$$
k(T)=A \operatorname{xp} \frac{E \alpha}{R T}
$$


where $E \alpha$ is the pyrolytic decomposition activation energy, A the pre-exponential factor and $\mathrm{R}$ the gas constant.

$f(\alpha)$ depends on the particular decomposition mechanism. The simplest and most frequently used model for $f(\alpha)$ in the analysis of TGA data is:

$$
f(\alpha)=(1-\alpha)^{n}
$$

where $\mathrm{n}$ is the order of reaction.

Insertion of eqs (5) and (6) into eq (1) gives

$$
\frac{d \alpha}{d t}=\beta \frac{d \alpha}{d T}=A(1-\alpha)^{n} e^{-\frac{E \alpha}{R T}}
$$

Flynn-Wall-Ozawa method [42] eq (7) is integrated using Doyle's approximation [43], and the result of the integration after taking logarithms is:

$$
\log \alpha \Rightarrow \frac{A F \alpha}{10 \frac{\mathrm{g}}{R}}-\quad \beta 1 \odot \mathrm{g} \quad-2.315 \frac{\mathscr{\sigma}}{R T}
$$

Thus, it is used to determine the activation energy for given values of conversion. The activation energy for different conversion values can be calculated from a $\log \beta$ versus $1 / \mathrm{T}$ plot.

The thermal degradation kinetic analysis of PPC and PPC/10wt\% PDEGA were determined with Flynn-Wall-Ozawa method. The Flynn-Wall-Ozawa plots are shown in Fig. 9. Figures 9 (a) and (b) show that the fitting lines are straight lines with a good correlation coefficient $r$, which indicates the applicability of Flynn-Wall-Ozawa to the

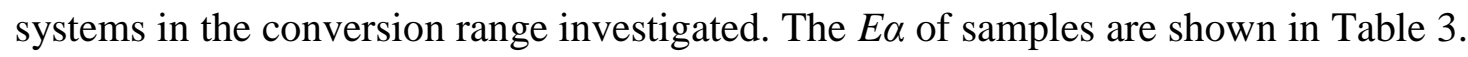
Evidently, the $E \alpha$ at the all stage of the degradation decreased with the addition of the PDEGA. And the E $\alpha$ of PPC/10wt\% PDEGA was lower than those of pure PPC at the same weight loss. It could be inferred that the early degradation of PDEGA caused a 
decrease in the activation energy.

\subsection{Mechanical properties}

The goal of adding plasticizer to PPC is to enhance plastic elongation and reduce brittleness while maintaining maximum polymer strength and stiffness. The stress-strain curves of neat PPC and PPC/PDEGA blends are shown in Fig. 10. It could be seen that neat PPC fractured at a lower tensile strain and no yield point was observed. The blends presented a yield point before the break and a subsequent plastic deformation which suggested that the addition of PDEGA was an effective means to improve the tensile toughness of PPC matrix. The stress-whitening behavior of the blends was observed during tensile deformation The results were in agreement with previous literature reports about the PLA/PDEGA blends [23].

The tensile strength, Young's modulus, and elongation at break for neat PPC and PPC/PDEGA blends with different PDEGA content are shown in Table 4. The tensile strength decreased from $37.1 \mathrm{MPa}$ for neat PPC to $22.2 \mathrm{MPa}$ for the $90 / 10$ PPC/PDEGA blend. The increase of PDEGA content to $20 \mathrm{wt} \%$ further decreased the yield stress to about 14.1 MPa. Some authors have reported similar decreased strength in other blends plasticized by PDEGA. The tensile strength for the PLA/PDEGA blends decreased as the content of PDEGA increased [23]. The tensile strength was dependent on the chemical bond forces and interaction between molecules, in particular the hydrogen bonding. The lower interaction between PPC macromolecules caused the decrease in the tensile strength for the blends when PDEGA was added in 
the blend.

Neat PPC exhibited an elongation at break value of $7.3 \%$ and it significantly increased with the addition of PDEGA. When the PDEGA content was $15 \mathrm{wt} \%$, the elongation at break increased to a maximum value (1300\%), which was about 178 times higher than that for neat PPC. In our previous works, we found that PDEGA could improve the flexibility of PLA by acting as a plasticizer [23]. The elongation at break for the PLA/PDEGA blends was slightly higher than that for neat PLA (4.5\%), and increased from 4.6 to $480 \%$ as the PDEGA content increased from 5 to $20 \mathrm{wt} \%$. For the PPC/PDEGA blends, the plasticizer weakened the interaction between polymer macromolecules and improved the flexibility of polymer chains, which could cause a great increase in elongation at break for the polymer. For the reason, the elongation at break for the PPC/PDEGA blends had a sharp increase when PDEGA was added.

The Young's modulus for neat PPC was $1380 \mathrm{MPa}$, which was higher than that for the blends. As the PDEGA content increased, the tensile modulus gradually decreased. At the PDEGA of $20 \mathrm{wt} \%$, the Young's modulus reached the lowest value (93.7 MPa). The results presented agreed with our previous work where the tensile modulus for the PLA/PDEGA blends decreased as the loading of PDEGA increased [23]. The Young's modulus was the ratio between the stress and the applied deformation which was also mainly depended on the chemical bond forces and the interaction between macromolecules. Therefore, the Young's modulus for the blends exhibited the slight decrease in higher loading of PDEGA similar with the change of the tensile strength. 


\section{Conclusions}

The ultimate objective of this study is to develop PDEGA as a biodegradable plasticizer for improving the mechanical properties of PPC. It was found that the PPC/PDEGA blend was partially miscible. The PPC/PDEGA blends exhibited lower storage modulus and complex viscosity than that for neat PPC, because of the plasticization effect of PDEGA. PDEGA significantly lowered the glass transition temperature of PPC and increased the segmental mobility of the PPC chains by plasticization. PDEGA promoted a decrease in thermal stability by its action to intersperse itself around polymers and by breaking polymer-polymer interactions. Tensile tests revealed that PDEGA markedly improved the flexibility of the PPC matrix. The elongation at break for the blends increased sharply as the PDEGA content was increased. At the PDEGA content of $20 \mathrm{wt} \%$, the elongation at break for the blends attained a maximum, which was about 178 times than that for neat PPC. In In conclusion, plasticized PPC were achieved and we developed these plasticizers really taking a satisfying effect on PPC.

Acknowledgements This work was supported by the fund of Chinese Science Academy (Changchun Branch) (No. 2014SYHZ0019), Development and Reform commission of Jilin Province of China (2015Y027), and the National Science Foundation of China (No. 51021003 and 51273201). 


\section{References}

[1] X.H. Li, Y.Z. Meng, G.Q. Chen, Q. Zhu, S.C. Tjong. Thermal properties and rheological behavior of biodegradable poly(propylene carbonate) derived from carbon dioxide and propylene oxide, J. Appl. Polym. Sci. 94 (2004) 711-716.

[2] R. Auras, B. Harte, S. Selke. An overview of polylactides as packaging, Mater. Macro. Biosci. 4 (2004) 835-864.

[3] C.H. Kim, K.Y. Cho, J.K. Park. Reactive blends of gelatinized starch and polycaprolactone-g-glycidyl methacrylate, J. Appl. Polym. Sci. 81 (2001) $1507-1516$.

[4] R.W. Lenz, R.H. Marchessault. Bacterial polyesters: Biosynthesis, biodegradable plastics and biotechnology, Biomacromolecule. 6 (2005) 1-8.

[5] S.W. Peng, Y.X. An, C. Cheng, B. Fei, Y.G. Zhuang, L.S. Dong. Miscibility and crystallization behavior of poly(3-hydroxyvalerate-co-3-hydroxyvalerate)/ poly(propylene carbonate) blends, J. Appl. Polym. Sci. 90 (2003) 4054-4060.

[6] N. Wang, J.G. Yu, X.F. Ma. Influence of citric acid on the properties of glycerol-plasticised cornstarch extrusion blends, Polym. Polym. Compos. 15 (2007) 545-552.

[7] S. Inoue, H. Koinuma, T. Tsuruta. Copolymerization of carbon dioxide and epoxide with organometallic compounds, Makro. Chem. 130 (1969) $210-220$.

[8] R.L. Paddock, S.T. Nguyen. Alternating copolymerization of $\mathrm{CO}_{2}$ and propylene oxide catalyzed by Co-III(salen)/Lewis base, Macromolecules. 238 
(2005) 6251-6253.

[9] R.S. Hahn, P.J. Fernstrom, U.S. Bhimaraja, B.J. Melody, R. Haha. Production of valve metal powder coated with polypropylene carbonate for capacitor anodes, involves tumbling valve metal powder in polypropylene carbonate solution to form coated powder which is dried and sieved. WO200121345-A1.

[10] P.J. Gagnon, D.W. Jordan, M.A. Raposa, D.J. Jossick, G.N. Martin. Flux composition used for coating brazing material, comprises flux, and elastomer selected from aliphatic carbonates, poly vinyl chlorides, latex compounds, silicates, polyesters, polyurethanes, aromatic polycarbonates or cellulose. WO2007058969.

[11] B.K. Wheatley, N.H. Lundstrom, R.D. Lynch, R.S. Scheffee, J.D. Martin. Solid gas generant composition employed in the inflation of vehicle occupant passive restraint systems e.g. air bag systems, comprises a nitramine, a binder and an oxidizer. WO200134537-A1.

[12] N.R. Anderson, R.K. Eyre, M.K. Keshavan, G. Rai, M. Keshavan, R.B. Crockett, R.L. Dixon, S.M. Packer. Formation of a polycrystalline ultra-hard material layer for compacts, e.g. for cutting tools-by placing layer of high shear compaction material contg. ultra-hard particles and organic binder adjacent cemented carbide substrate, heating, and high temp., high pressure processing. US5868885.

[13] Y. Hwang, M. Ree, H. Kim. Enzymatic degradation of poly(propylene carbonate) and poly(propylene carbonate-co-epsilon-caprolactone) synthesized via $\mathrm{CO}_{2}$ fixation, Catal. Today. 115 (2006) 288-294. 
[14] Robins P, Santangelo JG. Formation of in situ film dressing on animal tissue for enhancing wound healing, involves preparing application fluid comprising polyalkylene carbonate, applying fluid to animal tissue and forming film. CA2508295-A1.

[15] X.H. Li, Y.Z. Meng, Q. Zhu, Y. Xu, S.C. Tjong. Melt processable and biodegradable aliphatic polycarbonate derived from carbon dioxide and propylene oxide, J. Appl. Polym. Sci. 89 (2003) 3301-3308.

[16] D.D. Wu, W. Li, H.Y. Liang, S.R. Liu, J.Y. Fang, H.L. Zhang, H.X. Zhang, L.S. Dong. Thermal, Mechanical and Rheological Properties of Eco-friendly Poly(propylene carbonate)/Poly(1,2-propylene succinate) Blends. Chinese. J. Polym. Sci. 32 (2014) 914-922

[17] X.F. Ma, P.R. Chang, J.G. Yu, N. Wang. Preparation and properties of biodegradable poly(propylene carbonate)/thermoplastic dried starch composites, Carbohyd. Polym. 71 (2008) 229-234.

[18] X.F. Ma, J.G. Yu, N. Wang. Compatibility characterization of poly(lactic acid)/poly(propylene carbonate) blends, J. Polym. Sci. Part B: Polym. Phys. 44 (2006) 94-101.

[19] C. Chen, X.S. Zhou, Y.G. Zhuang, L.S. Dong. Thermal behavior and intermolecular interactions in blends of poly(3-hydroxybutyrate) and maleated poly(3-hydroxybutyrate) with chitosan, J. Polym. Sci. Part B: Polym. Phys. 43 (2005) 35-47.

[20] Z.H. Zhang, H.L. Zhang, Q.X. Zhang, Q.H. Zhou, H.F. Zhang, Z.S. Mo. 
Thermotropic liquid crystallinity, thermal decomposition behavior, and aggregated structure of poly(propylene carbonate)/ethyl cellulose blends, J. Appl. Polym. Sci. 100 (2006) 584-592.

[21] T. Yu, Y. Zhou, Y. Zhao, K.P. Liu, E.Q. Chen, D.J. Wang. Hydrogen bonded thermostable liquid crystalline complex formed by biodegradable polymer and amphiphilic molecules, Macromolecules. 41 (2008) 3175-3180.

[22] X.F. Wu, J.B. Zhao, W.T. Yang. Synthesis method of biodegradable polydiethylene glycol adipate with high molecular weight, J. Beijing. Univ. Chem. Technol. 28 (2001) 23-26.

[23] H.Y. Liang, Y.P. Hao, S.R. Liu, H.L. Zhang, Y.S. Li, L.S. Dong, H.X. Zhang Thermal, rheological, and mechanical properties of polylactide/poly(diethylene glycol adipate), Polym. Bull. 70 (2013) 3487-3500.

[24] G.H. Yew, A.M.M. Yusof, Z.A.M. Ishak, U.S. Ishiaku. Water absorption and enzymatic degradation of poly(lactic acid)/rice starch composites, Polym. Degrad. Stab. 90 (2005) 488-500.

[25] I.M. Thakore, S. Desai, B.D. Sarawade, S. Devi. Studies on biodegradability, morphology and thermomechanical properties of LDPE/modified starch blends, Eur. Polym. Mater. 37 (2001) 151-160.

[26] J.S. Choi, W.H. Park. Effect of biodegradable plasticizers on thermal and mechanical properties of poly(3-hydroxybutyrate), Polym. Test. 23 (2004) $455-460$.

[27] E. Piorkowska, Z. Kulinski, A. Galeski, R. Masirek. Plasticization of 
semicrystalline poly(L-lactide) with poly(propylene glycol), Polymer. 47 (2006) $7178-7188$.

[28] F. Ali, Y.W. Chang, S.C. Kang, J.Y. Yoon. Thermal, mechanical and rheological properties of poly (lactic acid)/epoxidized soybean oil blends, Polym. Bull. 62 (2009) 91-98.

[29] N. Ljungberg, B. Wesslen. Tributyl citrate oligomers as plasticizers for poly (lactic acid): thermo-mechanical film properties and aging. Polymer. 44 (2003) $7679-7688$.

[30] N. Ljungberg, B. Wesslen. The effects of plasticizers on the dynamic mechanical and thermal properties of poly(lactic acid). J. Appl. Polym. Sci. 86 (2002) $1227-1234$.

[31] J. Cowie. Blackie Academic and Professional. Polym. In. Solu. (1991) 178-179.

[32] H. Li, M.A. Huneault. Effect of nucleation and plasticization on the crystallization of poly(lactic acid), Polymer. 48 (2007) 6855-6866.

[33] K. Cho, J. Yang, C. Park. The effect of rubber particle size on toughening behavior of rubber-modified poly(methyl methacrylate) with different test methods, Polymer. 39 (1998) 3073-3081.

[34] K. Cho, B.H. Lee, K.M. Hwang, H. Lee, S. Choe. Rheological and mechanical properties in polyethylene blends, Polym. Eng. Sci. 38 (1998) 1969-1975.

[35] H. Kwak, D. Rana, S. Choe. Melt rheology of binary blends of metalocene polyethylene with conventional polyolefins. J. Ind. Eng. Chem. 6 (2000) $107-114$. 
[36] H. Kwak, D. Rana, K. Choe, J. Rhee, T. Woo, B.H. Lee, S. Choe. Binary blends of metallocene polyethylene with conventional polyolefins: Rheological and morphological properties, Polym. Eng. Sci. 40 (2000) 1672-1681.

[37] M. Joshi, B.S. Butola, G. Simon, N. Kukaleva. Rheological and viscoelastic behavior of hdpe/octamethyl-poss nanocomposites, Macromolecules. 39 (2006) 1839-1849.

[38] N. Song, L. Zhu, X. Yan, Y. Xu, X. Xu. Effect of blend composition on the rheology property of polypropylene/poly (ethylene-1-octene) blends. J. Mater. Sci. 43 (2008) 3218-3222.

[39] M. Murariu, A.D. Ferreira, M. Alexandre, P. Dubois. Polylactide (PLA) designed with desired end-use properties: 1. PLA compositions with low molecular weight ester-like plasticizers and related performances, Polym. Adv. Technol. 19 (2008) 636-646.

[40] Y. Lemmouchi, M. Murariu, A.M. Dos Santos, A.J. Amass, E. Schacht, P. Dubois. Plasticization of poly(lactide) with blends of tributyl citrate and low molecular weight poly(D,L-lactide)-b-poly(ethylene glycol) copolymers. Eur. Polym. J. 45 (2009) 2839-2848.

[41] P.H. Daniels. A Brief Overview of Theories of PVC Plasticization and Methods Used to Evaluate PVC-Plasticizer Interaction, J. Vinyl. Addit. Technol. 15 (2009) 219-223.

[42] T. Ozawa. A New Method of Analyzing Thermogravimetric Data, Bull. Chem. Soc. Jpn. 38 (11) (1965) 1881-1886. 
[43] C.D. Doyle. Kinetic Analysis of Thermogravimetric Data*, J. Appl. Polym. Sci. 5 (15) (1961) 285-292.

\section{Figure captions}

Fig. 1. SEM micrographs of cryogenically fracture surfaces of PPC/PDEGA blends: (a) $95 / 5$, (b) $90 / 10$, (c) $85 / 15$, and (d) $80 / 20$.

Fig. 2. Variations of MFI for neat PPC and PPC/PDEGA blends.

Fig. 3. Plots of complex viscosity $\left(\eta^{*}\right)$ versus angular frequency $(\omega)$ for neat PPC and PPC/PDEGA blends.

Fig. 4. Plots of Cole-Cole for neat PPC and PPC/PDEGA blends.

Fig. 5. Plots of (a) dynamic storage modulus $\left(G^{\prime}\right)$ and (b) loss modulus $\left(G^{\prime \prime}\right)$ versus angular frequency $(\omega)$ for neat PPC and PPC/PDEGA blends.

Fig. 6. Loss storage modulus versus temperature traces of PPC/PDEGA blends with different PDEGA contents.

Fig. 7. DSC thermograms of neat PPC and PPC/PDEGA blends.

Fig. 8. Effect of PDEGA on the thermal stability of PPC: (a) TGA and (b) DTG.

Fig. 9. Flynn-Wall-Ozawa plots at the following different weight losses of (a) PPC and (b) PPC/10wt\% PDEGA.

Fig. 10. Stress-strain curves of neat PPC and PPC/PDEGA blends. 
Table 1

Some parameters related to the solubility parameter $\delta$ of PPC and PDEGA.

\begin{tabular}{c|ccc}
\hline & $\begin{array}{c}\rho \\
\left(\mathrm{g} / \mathrm{cm}^{3}\right)\end{array}$ & $\begin{array}{c}M_{0} \\
(\mathrm{~g} / \mathrm{mol})\end{array}$ & $\begin{array}{c}\delta \\
\left(\mathrm{J} / \mathrm{cm}^{3}\right)^{1 / 2}\end{array}$ \\
\hline PPC & 1.20 & 102 & 19.4 \\
PDEGA & 1.05 & 200 & 18.9 \\
\hline
\end{tabular}




\section{Table 2}

Thermal properties of neat PPC and PPC/PDEGA blends.

\begin{tabular}{c|c|c|c|c|c}
\hline $\begin{array}{c}\text { PPC/PDEGA } \\
(\mathrm{w} / \mathrm{w})\end{array}$ & $\begin{array}{c}T_{\mathrm{g}}^{\mathrm{a}}, \mathrm{PPC} \\
\left({ }^{\mathrm{O}} \mathrm{C}\right)\end{array}$ & $\begin{array}{c}T_{\mathrm{g}}^{\mathrm{b}}, \mathrm{PPC} \\
\left({ }^{\circ} \mathrm{C}\right)\end{array}$ & $\begin{array}{c}T_{\mathrm{g}}^{\mathrm{b}}, \text { PDEGA } \\
\left({ }^{\circ} \mathrm{C}\right)\end{array}$ & $\begin{array}{c}T_{\text {onset }} \\
\left({ }^{\circ} \mathrm{C}\right)\end{array}$ & $\begin{array}{c}T_{\max } \\
\left({ }^{\circ} \mathrm{C}\right)\end{array}$ \\
\hline $100 / 0$ & 32.6 & 33.4 & - & 255.4 & 268.4 \\
$95 / 5$ & 24.6 & 25.0 & - & 238.9 & 246.4 \\
$90 / 10$ & 19.1 & 18.2 & -57.4 & 237.1 & 240.9 \\
$85 / 15$ & 17.3 & 15.2 & -62.3 & 235.0 & 239.7 \\
$80 / 20$ & 14.2 & 10.8 & -67.2 & 233.5 & 237.1 \\
$0 / 100$ & - & - & - & 218.6 & 393.3 \\
\hline
\end{tabular}

${ }^{a}$ Obtained from DSC analysis.

${ }^{\mathrm{b}}$ Obtained from DMA analysis. 
Table 3

Activation energies of PPC and PPC/10wt\% PDEGA by Flynn-Wall-Ozawa method.

\begin{tabular}{cccccc}
\hline \multirow{2}{*}{ Conversion $\alpha$} & \multicolumn{2}{c}{ PPC } & & \multicolumn{2}{c}{ PPC/10wt\% PDEGA } \\
\cline { 2 - 3 } \cline { 5 - 6 } & $\mathrm{E}(\mathrm{KJ} / \mathrm{mol})$ & $\mathrm{r}$ & & $\mathrm{E}(\mathrm{KJ} / \mathrm{mol})$ & $\mathrm{r}$ \\
\hline 0.1 & 136.8 & 0.9985 & & 117.3 & 0.9987 \\
0.2 & 126.7 & 0.9984 & & 112.8 & 0.9981 \\
0.3 & 122.7 & 0.9978 & & 110.3 & 0.9977 \\
0.4 & 117.6 & 0.9977 & & 107.7 & 0.9964 \\
0.5 & 112.8 & 0.9946 & & 104.5 & 0.9937 \\
0.6 & 107.0 & 0.9933 & & 104.4 & 0.9926 \\
0.7 & 100.3 & 0.9879 & 98.9 & 0.9882 \\
0.8 & 88.5 & 0.9814 & 90.8 & 0.9819 \\
\hline
\end{tabular}


Table 4

Mechanical properties of neat PPC and PPC/PDEGA blends.

\begin{tabular}{|c|c|c|c|}
\hline $\begin{array}{c}\text { PPC/PDEGA } \\
(\mathrm{w} / \mathrm{w})\end{array}$ & $\begin{array}{l}\text { Young's } \\
\text { Modulus } \\
\text { (MPa) }\end{array}$ & $\begin{array}{l}\text { Tensile } \\
\text { strength } \\
(\mathrm{MPa})\end{array}$ & $\begin{array}{c}\text { Elongation at } \\
\text { break } \\
(\%)\end{array}$ \\
\hline $100 / 0$ & $1080 \pm 23$ & $37.1 \pm 2.8$ & $7.3 \pm 0.5$ \\
\hline $95 / 5$ & $364 \pm 10$ & $23.5 \pm 1.9$ & $780 \pm 23.6$ \\
\hline $90 / 10$ & $183 \pm 12$ & $22.2 \pm 2.6$ & $1200 \pm 30.2$ \\
\hline $85 / 15$ & $130 \pm 8.6$ & $22.6 \pm 1.5$ & $1300 \pm 31.4$ \\
\hline $80 / 20$ & $93.7 \pm 3.9$ & $14.1 \pm 0.9$ & $1300 \pm 30.6$ \\
\hline
\end{tabular}




\section{Figure 1}

(a)

Acc. V Spot Maqn Det WD Exp
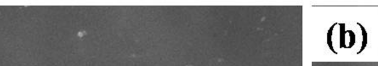

(b)

Acc.V Spot Magn Det WD Exp $10.0 \mathrm{kV} 3.0 \quad 4000 \mathrm{x} \quad \mathrm{SE} \quad 8.8 \quad 1$
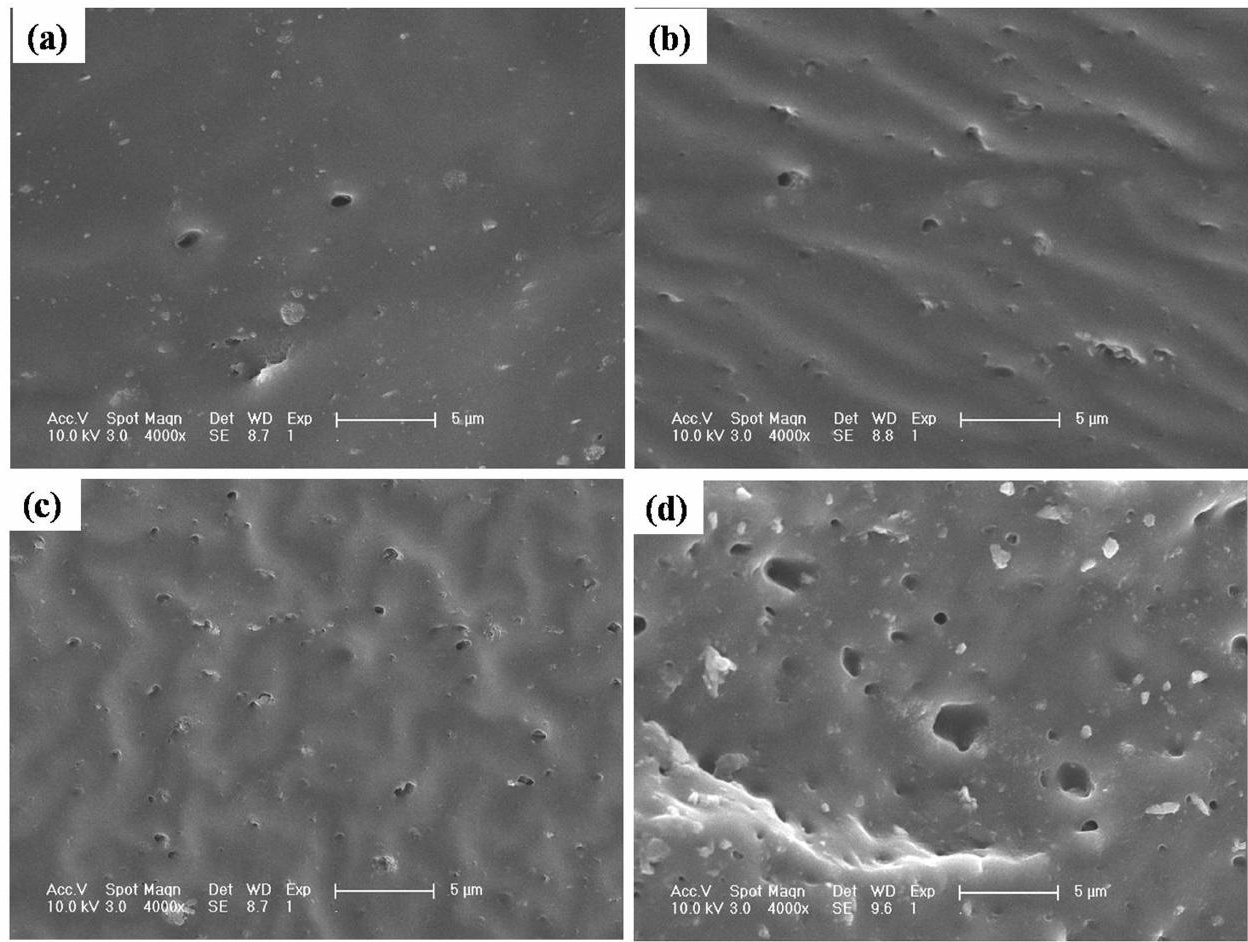
Figure 2

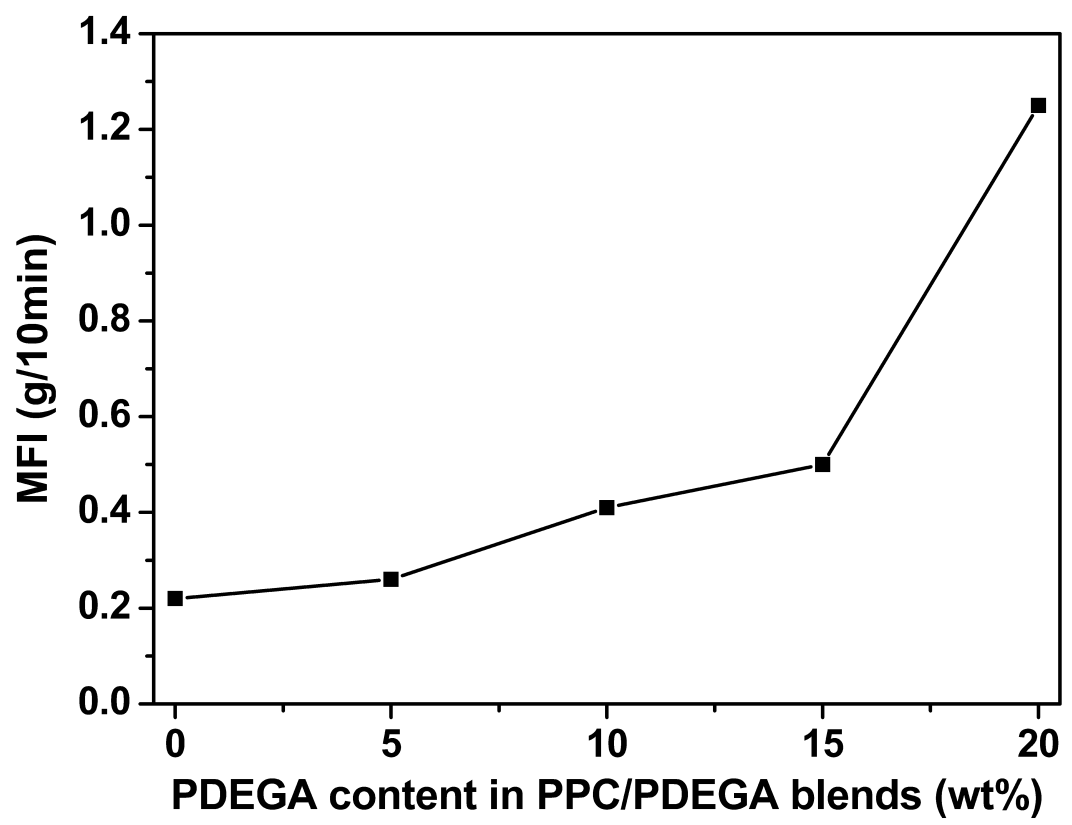


Figure 3

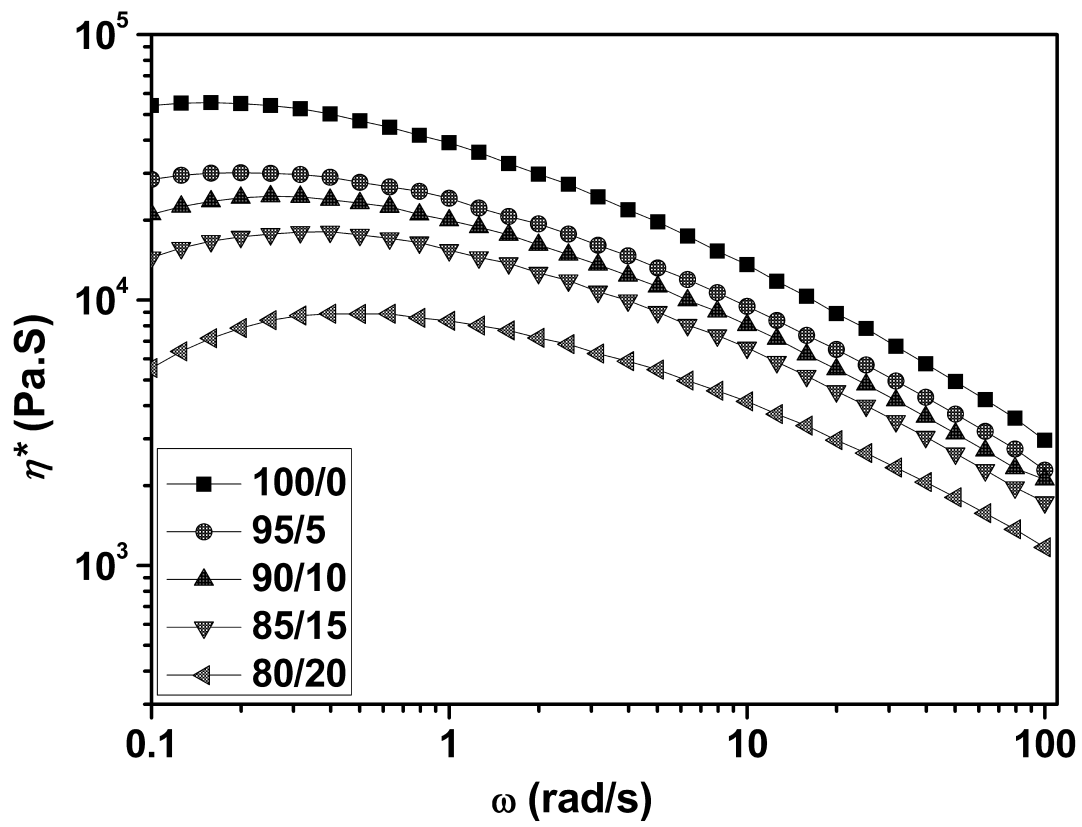


Figure 4

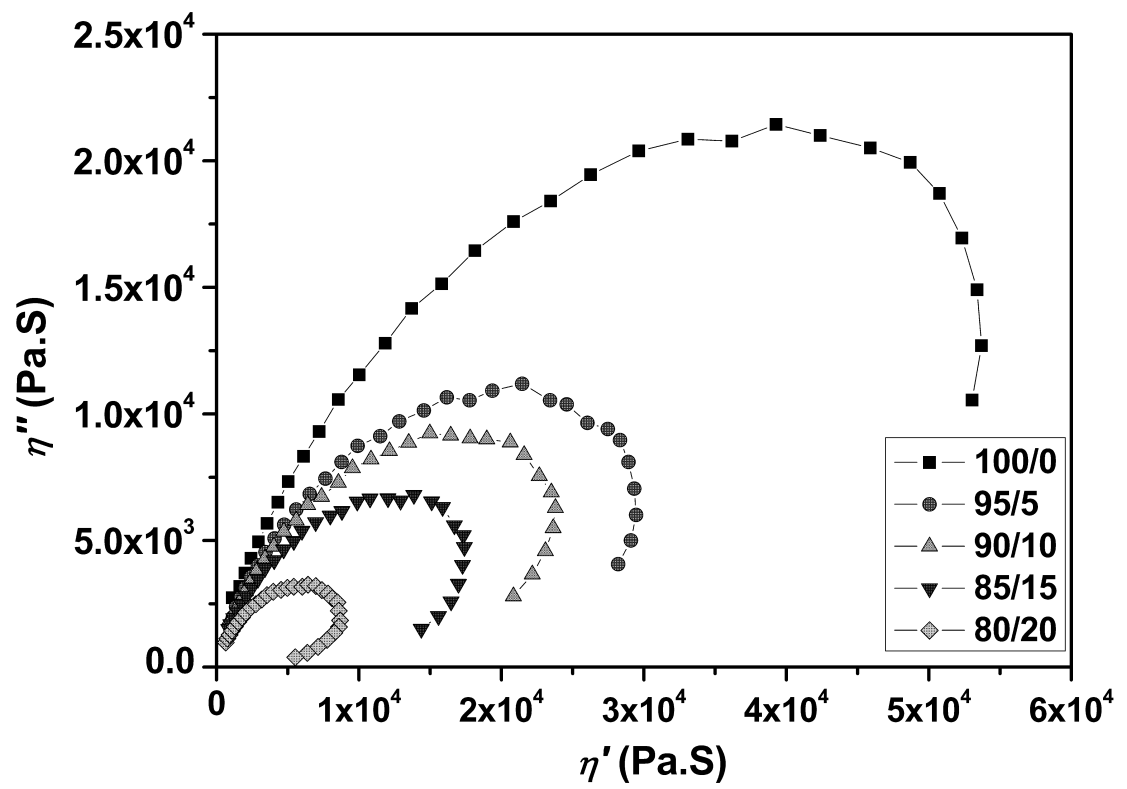


Figure 5a

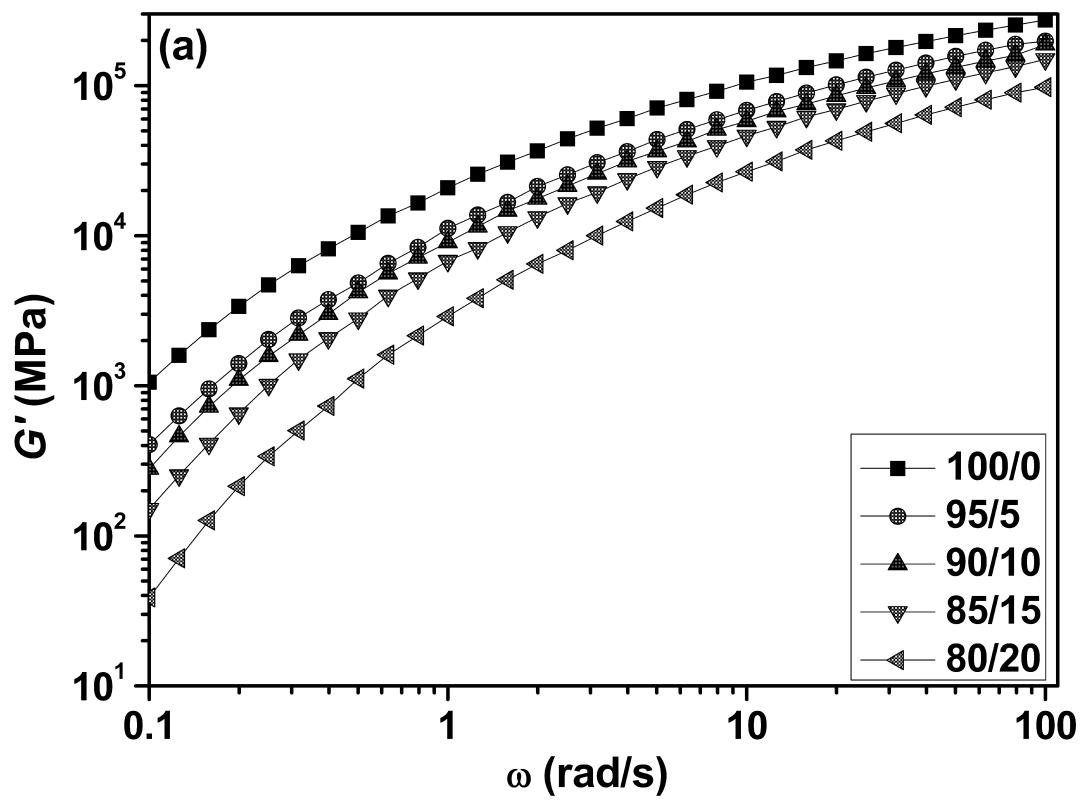


Figure 5b

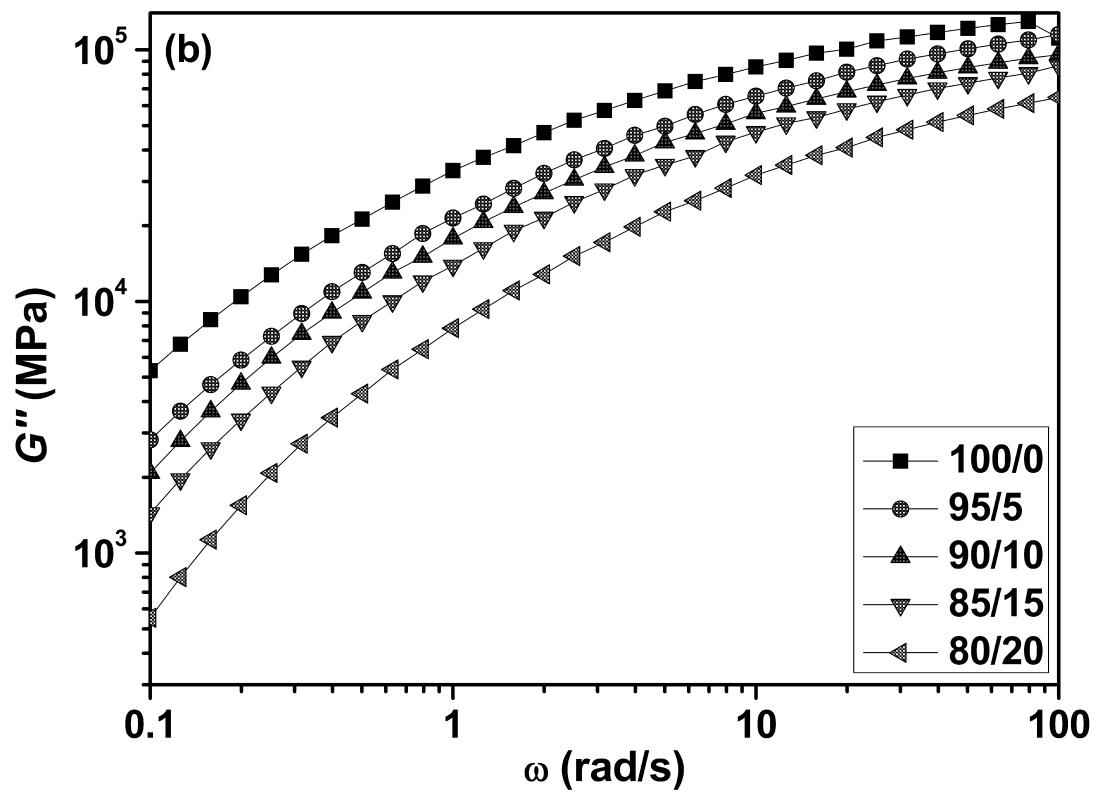


Figure 6

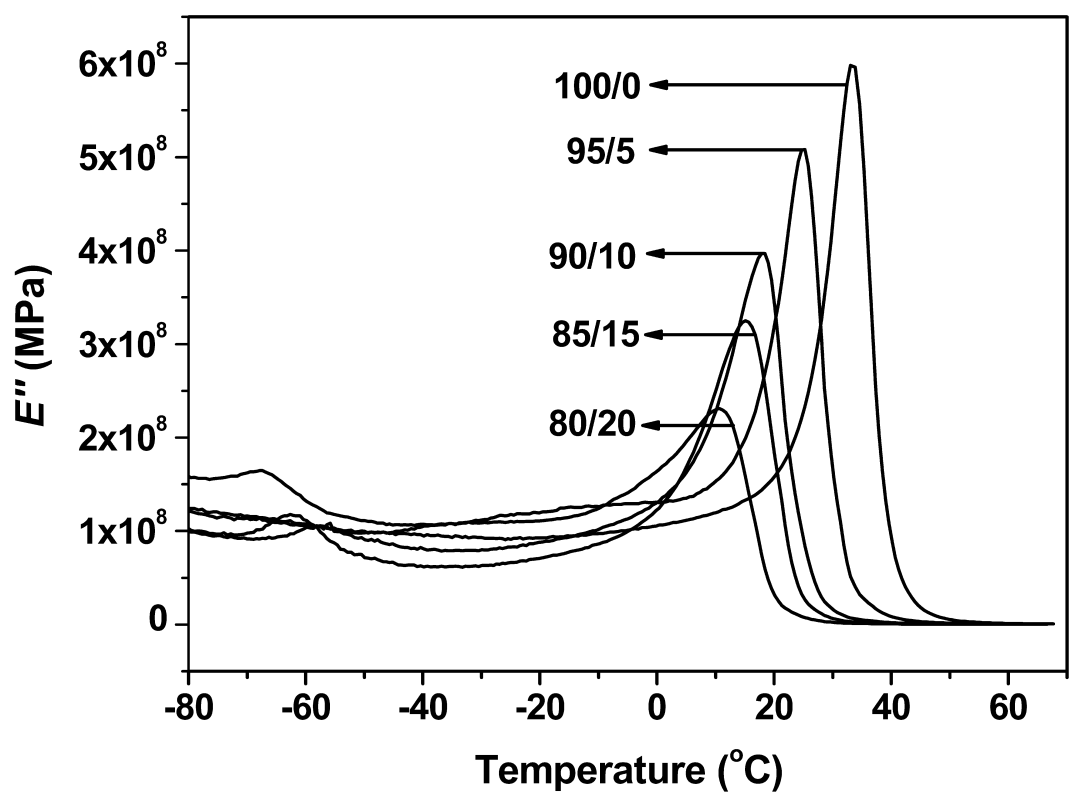


Figure 7

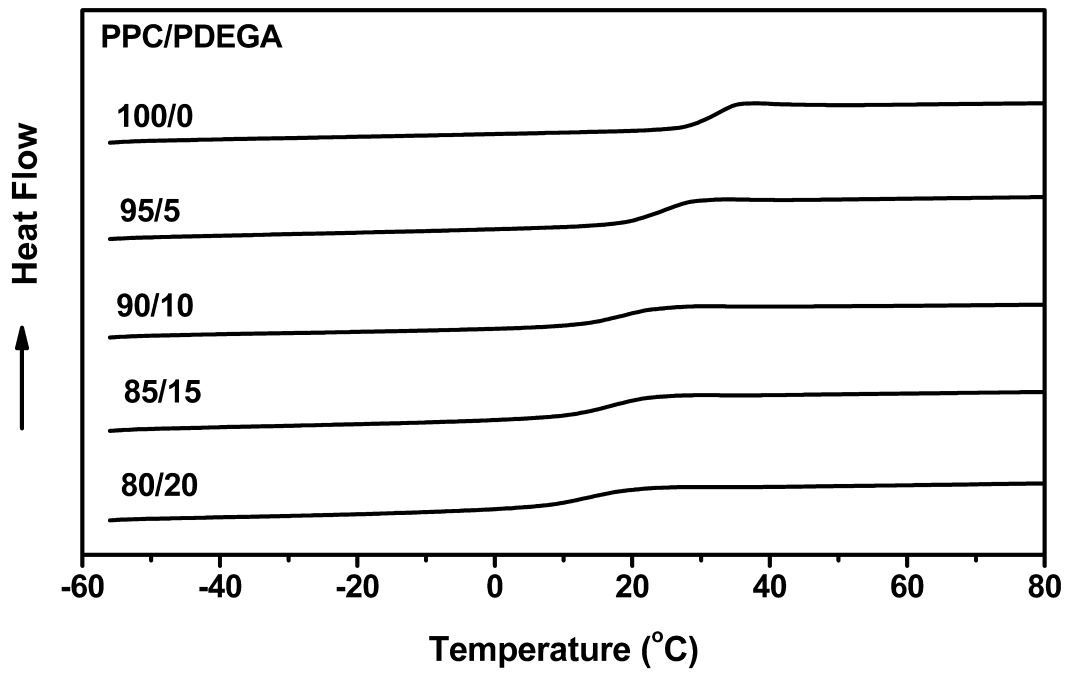


Figure $8 a$

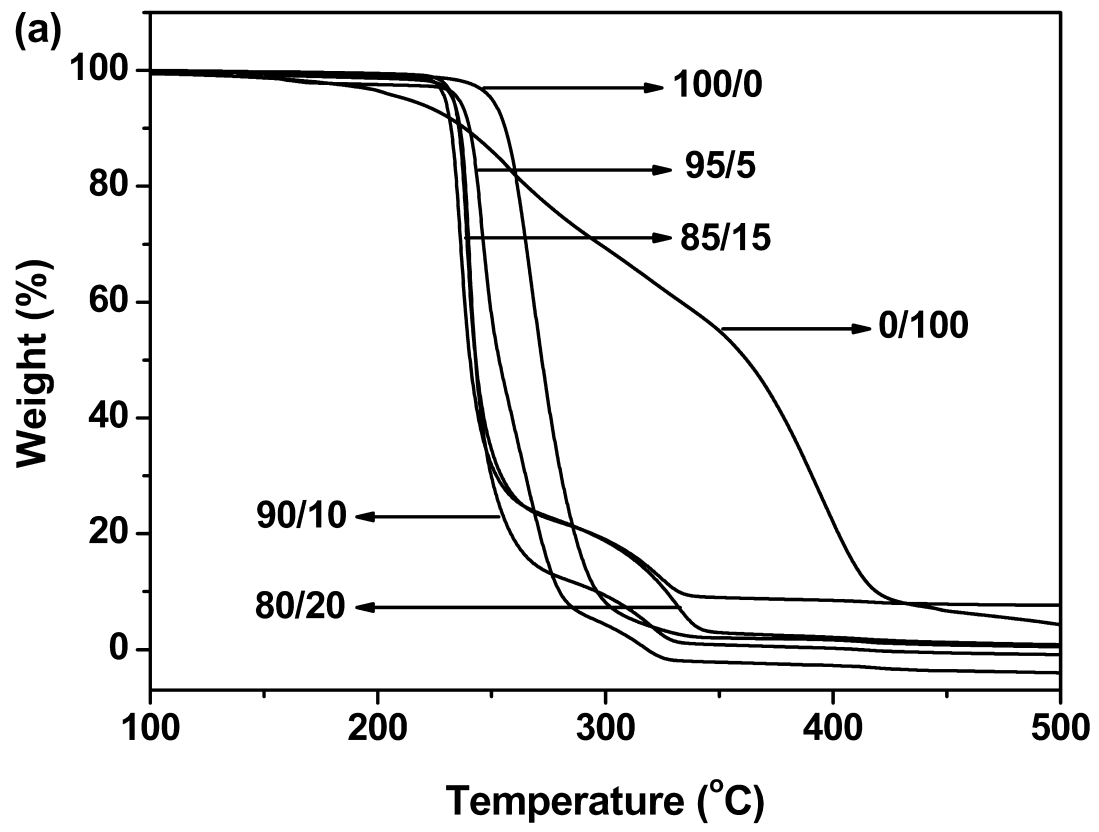


Figure $8 b$

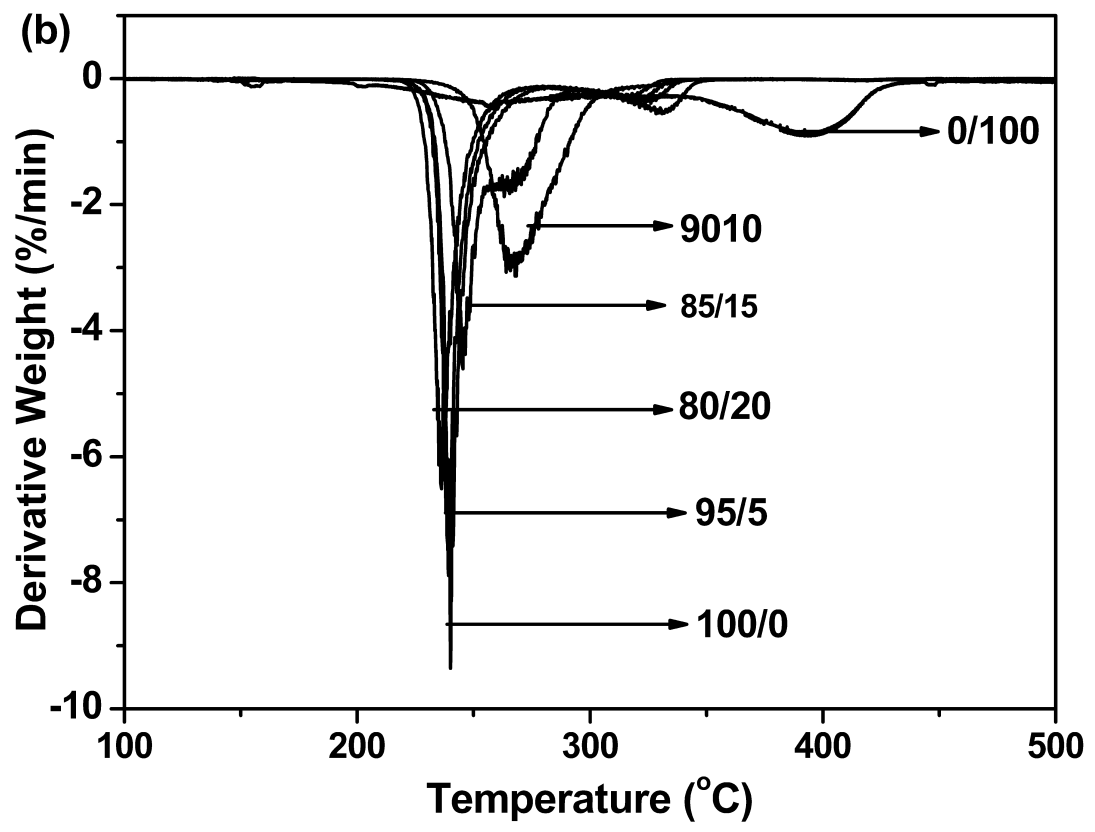


Figure 9a

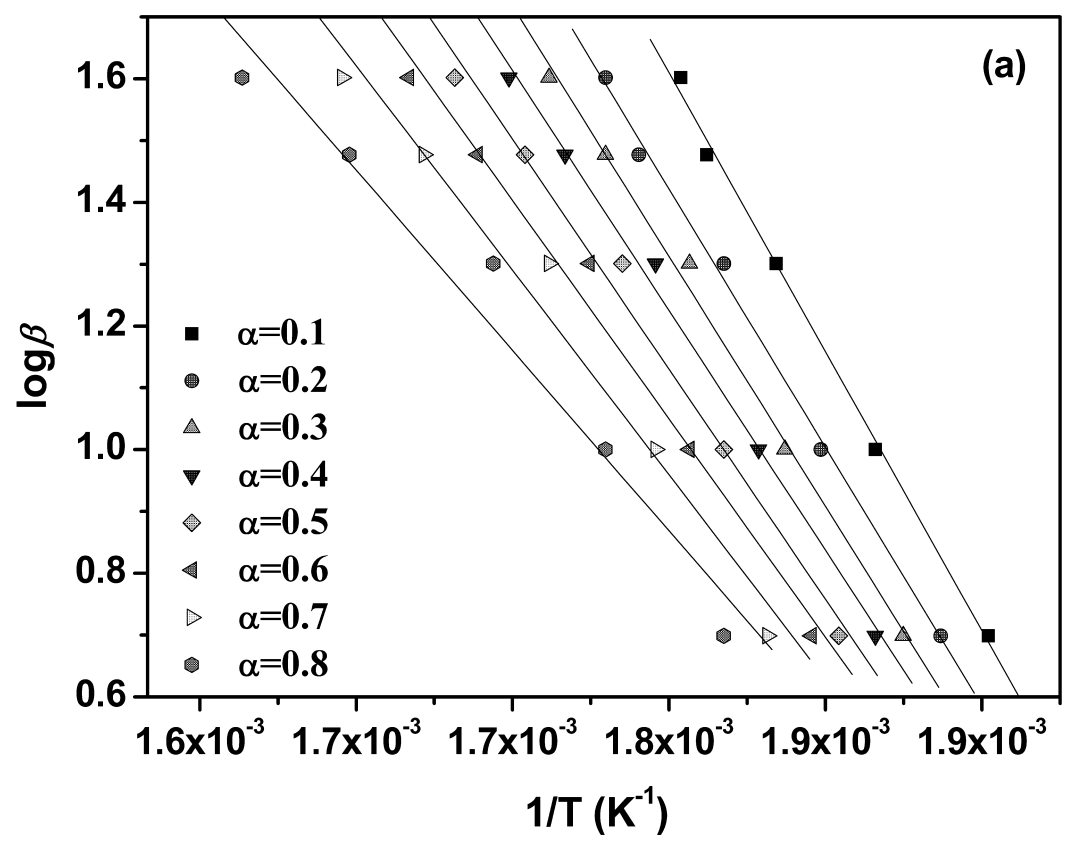


Figure 9b

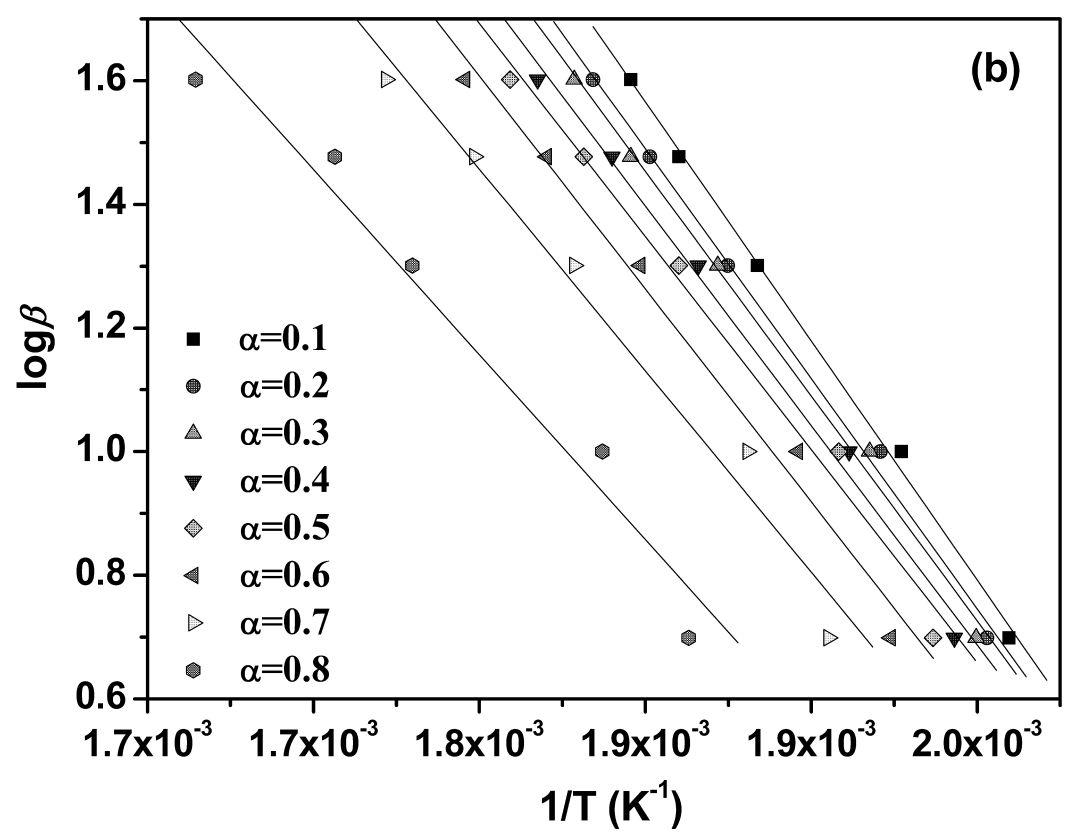


Figure 10

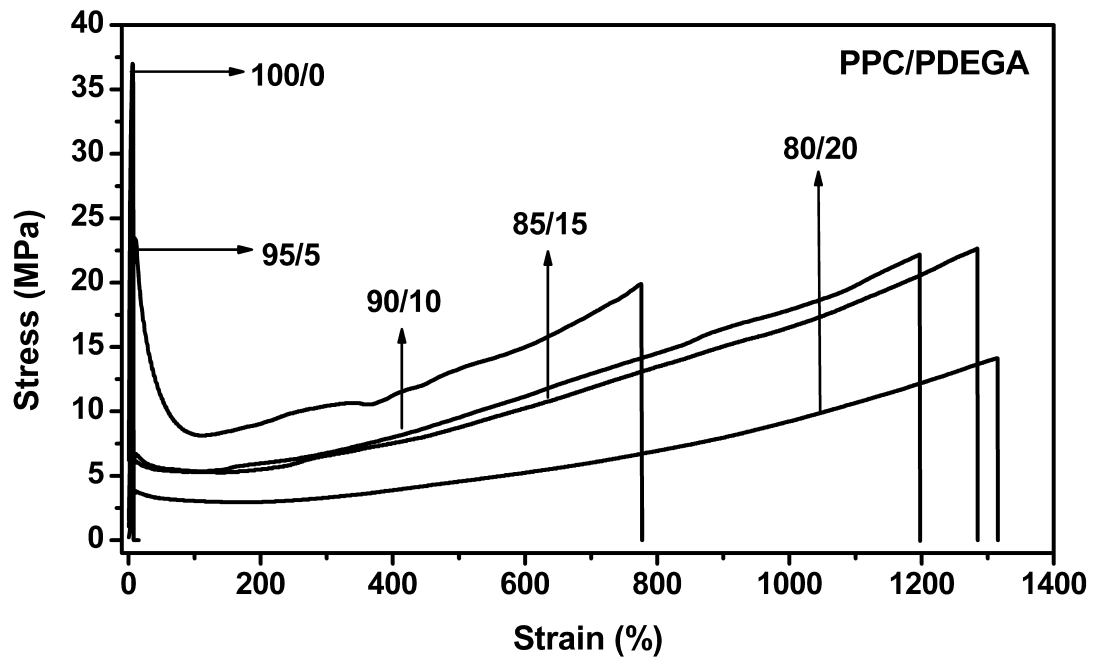

